\title{
Connecting to the oceans: supporting ocean literacy and public engagement
}

\author{
Rachel Kelly (D) Karen Evans • Karen Alexander • Silvana Bettiol • \\ Stuart Corney $\cdot$ Coco Cullen-Knox $\cdot$ Christopher Cvitanovic $\cdot$ Kristy de Salas • \\ Gholam Reza Emad - Liam Fullbrook - Carolina Garcia - Sierra Ison • \\ Scott Ling • Catriona Macleod • Amelie Meyer - Linda Murray • \\ Michael Murunga $\cdot$ Kirsty L. Nash · Kimberley Norris • Michael Oellermann • \\ Jennifer Scott • Jonathan S. Stark • Graham Wood • Gretta T. Pecl
}

Received: 24 April 2020/Accepted: 23 October 2020/Published online: 10 February 2021

(C) Springer Nature Switzerland AG 2021

\begin{abstract}
Improved public understanding of the ocean and the importance of sustainable ocean use, or ocean literacy, is essential for achieving global commitments to sustainable development by 2030 and beyond. However, growing human populations (particularly in mega-cities), urbanisation and socioeconomic disparity threaten opportunities for people to engage and connect directly with ocean environments. Thus, a major challenge in engaging the whole of society in achieving ocean sustainability by 2030 is
\end{abstract}

Electronic supplementary material The online version of this article (https://doi.org/10.1007/s11160-020-09625-9) contains supplementary material, which is available to authorized users.

R. Kelly $(\bowtie) \cdot$ K. Alexander · S. Corney ·

C. Cullen-Knox · C. Cvitanovic .

L. Fullbrook · S. Ison - C. Macleod .

M. Murunga · K. L. Nash · G. T. Pecl

Centre for Marine Socioecology, University of Tasmania,

Hobart, TAS 7005, Australia

e-mail: r.kelly@utas.edu.au

K. Evans · S. Ison

CSIRO Oceans and Atmosphere, Castray Esplanade,

Hobart, TAS 7001, Australia

K. Alexander $\cdot$ S. Corney $\cdot$ S. Ling ·

C. Macleod - A. Meyer - M. Murunga ·

K. L. Nash · M. Oellermann - G. T. Pecl

Institute for Marine and Antarctic Studies, Hobart,

TAS 7001, Australia to develop strategies to improve societal connections to the ocean. The concept of ocean literacy reflects public understanding of the ocean, but is also an indication of connections to, and attitudes and behaviours towards, the ocean. Improving and progressing global ocean literacy has potential to catalyse the behaviour changes necessary for achieving a sustainable future. As part of the Future Seas project (https://futureseas2030.org/), this paper aims to synthesise knowledge and perspectives on ocean literacy from a range of disciplines, including but not exclusive to marine biology, socio-ecology, philosophy, technology, psychology, oceanography and human health. Using examples from the literature, we outline

\author{
S. Bettiol \\ College of Health and Medicine, University of Tasmania, \\ Hobart, TAS 7005, Australia \\ C. Cullen-Knox \\ The Media School, University of Tasmania, Battery Point, \\ Salamanca Square, TAS 7004, Australia \\ C. Cvitanovic \\ Australian National Centre for the Public Awareness of \\ Science, Australian National University, Canberra, \\ ACT 0200, Australia \\ K. de Salas · C. Garcia \\ School of Technology, Environments and Design, \\ University of Tasmania, Hobart, TAS 7005, Australia
}


the potential for positive change towards a sustainable future based on knowledge that already exists. We focus on four drivers that can influence and improve ocean literacy and societal connections to the ocean: (1) education, (2) cultural connections, (3) technological developments, and (4) knowledge exchange and science-policy interconnections. We explore how each driver plays a role in improving perceptions of the ocean to engender more widespread societal support for effective ocean management and conservation. In doing so, we develop an ocean literacy toolkit, a practical resource for enhancing ocean connections across a broad range of contexts worldwide.

Keywords Communication - Education - Future seas · Interdisciplinary · Ocean literacy $\cdot$ Sustainable 2030

\section{Introduction}

The ocean is threatened by a growing list of stressors, including climate change (Poloczanska et al. 2016; Pecl et al. 2017; IPCC 2019), overfishing (Rousseau et al. 2019) and pollution (Villarrubia-Gómez et al. 2018; Vince and Hardesty 2019). Together, these stressors demonstrate an urgent and escalating global need for improved understanding of the ocean and for sustainable management of the marine environment. The impact of these multiple stressors is projected to increase as the global human population expands to an expected 8.5 billion by 2030 (Jouffray et al. 2020). Addressing these environmental challenges requires collective action at local, national, regional and global

\footnotetext{
G. R. Emad

Australian Maritime College, University of Tasmania

Newnham, Hobart, TAS 7248, Australia

L. Fullbrook

School of Social Sciences, University of Tasmania,

Hobart, TAS 7005, Australia

L. Murray

College of Health, Massey University, Wellington, New

Zealand
}

K. Norris · J. Scott

School of Psychological Sciences, University of

Tasmania, Hobart, TAS 7005, Australia scales. However, marine environments are intrinsically complex and embedded in dynamic socioecological systems. Overlooking human and social dimensions of the ocean is one of the most common factors behind conservation failure, highlighting the urgent need for actions that enhance peoples' understanding of, connection to, and resulting pro-environmental attitudes and behaviours towards the ocean (Catalano et al. 2019; Stoll-Kleemann 2019).

Global attention is increasingly focused on strategies for fostering attitudes and behaviours that support the sustainable use of natural environments (Bamberg and Moser 2007; Duarte et al. 2020). Enhancing public awareness and knowledge of the ocean is essential to strengthen connection to the ocean, and increase motivation for behaviour change and support for solutions that can reduce or prevent human impacts on marine environments and resources (Schoedinger et al. 2005). Furthermore, engaging society and communities in ocean dialogue can lead to the collective production of new knowledge and the exchange of non-scientific knowledge, including local, traditional and Indigenous knowledge (Thornton and Maciejewski Scheer 2012; Clarke et al. 2013). The UN Decade of Ocean Science for Sustainable Development 2021-2030 highlights the need for a 'rigorous ocean literacy programme of activities' to increase public awareness and knowledge that can guide sustainable behaviours and inform decisionmaking (UN 2018a). In particular, the focus of this UN Ocean Decade emphasises the value of non-scientific knowledges, and the role of inclusive approaches that can encourage better stewardship and improve the management of ocean resources (UN 2019b; Pendleton et al. 2020). The UN Sustainable Development

\author{
M. Oellermann \\ Aquatic Systems Biology Unit, Technical University of \\ Munich, Freising, Germany \\ J. S. Stark \\ Australian Antarctic Division, Kingston, \\ TAS 7050, Australia \\ G. Wood \\ School of Humanities, University of Tasmania, \\ Launceston, TAS 7250, Australia
}


Goals (SDGs) include a focus on improving conditions in the global oceans (e.g. \#14: Life below water) and the Convention for Biological Diversity has also set global goals for marine environments (e.g. Aichi Target 11). An aim to increase global ocean literacy (and stewardship) demands improving social engagement with ocean issues (Mogias et al. 2019) and enhancing community connections to the ocean (Schuldt et al. 2016).

\section{Ocean literacy}

Ocean literacy is an understanding of the ocean's influence on society and the society's influence on the ocean (Schoedinger et al. 2010; Fauville et al. 2019). An ocean literate individual understands fundamental concepts about ocean functioning, is able to discuss ocean issues in meaningful ways, and is also capable of making informed and responsible decisions in regards to the ocean and its resources (Cava et al. 2005; Fauville et al. 2019; Mogias et al. 2019). Ocean literacy is a broader expansion of the traditional notion of 'literacy' (UNESCO 2006) and is based on seven key principles (see Box 1). It is not just a measure of what people know, but is also an indication of their attitudes, behaviours, and ability to communicate about ocean issues (Brennan et al. 2019). Building ocean literacy amongst communities or groups of individuals is an approach to encourage responsible public behaviour towards the ocean and its resources (Fielding et al. 2019). The 'goal' of ocean literacy initiatives is to enable behaviour change, whereby citizens engage in sustainable actions to achieve solutions to marine issues (Ashley et al. 2019). In contrast, a lack of ocean literacy presents a significant obstacle to engaging society in environmentally sustainable behaviours (McCauley et al. 2019).

Box 1 Seven principles of ocean literacy, as identified by Schoedinger et al. 2010

1 The earth has one big ocean with many features

2 The ocean and life in the ocean shape the features of Earth

3 The ocean is a major influence on weather and climate

4 The ocean makes the Earth habitable

5 The ocean supports a great diversity of life and ecosystems

6 The ocean and humans are inextricably interconnected

7 The ocean is largely unexplored
The modern (and to date, predominately Western) ocean literacy movement began in the United States in the 2000s, and since then has expanded internationally (Fauville et al. 2019). This movement developed largely in response to global recognition of marine environmental deterioration and the resultant need to improve public understanding of the oceans (Soares 1998; PewOceansCommission 2003). The first ocean literacy framework was produced by a grassroots collaboration of concerned scientists and educators (Schoedinger et al. 2005) and many other ocean literacy frameworks and guidance tools have been developed since (see Appendix A). These myriad frameworks centre primarily around educational programmes for children and youths, and focus on formal and school-based curricula. This is unsurprising, as environmental learning initiatives typically target children and young people, however, it is unrealistic and unfair to assign responsibility of the oceans solely to future generations (Pahl et al. 2017). There is an urgent need to educate and engage all levels of society (Hoegh-Guldberg and Bruno 2010). Whilst the ocean literacy principles are widely relevant to the general adult population, a more universal and overarching guidance tool for groups across all socio-demographics (i.e. marine managers, scientists, knowledge brokers, policy-makers, communities; in developed and developing countries; and in marine and landlocked regions, etc.) is needed.

Connectedness to nature (i.e. feeling a connection or affinity to nature) influences attitudes and behaviours that support the sustainable use of natural environments (Martin et al. 2016; Moreton et al. 2019; Song et al. 2019). For example, personal attachment to the marine environment is central to the development of marine citizenship (McKinley and Fletcher 2012). However, a significant challenge in engaging communities with the ocean is that, in reality, most people only spend a limited part of their life experiencing ocean environments (Cigliano et al. 2015). Disconnectedness is strongly linked to poor personal understanding and awareness of marine issues (McKinley and Fletcher 2010), and is likely exacerbated by modern lifestyles and technologies that have resulted in people progressively spending more time indoors (Pergams and Zaradic 2008; Basile 2016) and less time outside experiencing natural environments (Cox et al. 2017; Bratman et al. 2019; Truong and Clayton 2020). 
Increasing urbanisation is another factor contributing to global disconnectedness to the ocean. It is estimated that over two-thirds of the world's population will live in cities by 2030 (UN 2018b). Growing coastal populations and associated urbanisation are progressively reducing access to ocean environments. For example, as populations expand and become more urbanised, people progressively are situated in areas further from the coast. Lack of transport from regions further away from the coast further exacerbates this disconnection to the coast. Further, as coastal regions are purchased by investors, public access to the ocean is increasingly restricted (Roy et al. 2018; KomugabeDixson et al. 2019). The global decline of traditional cultures that support local connections with the ocean is also contributing to increasing disconnectedness (Friedlander 2018); as younger generations move into urban environments and adopt 'modern' lifestyles, or as population diversity increases, local knowledge and practices are diluted and lost (Komugabe-Dixson et al. 2019).

In this paper, we identify drivers of ocean literacy from local through to global scales, building upon the existing literature. We elucidate trends and directions to illustrate our vision and highlight relevant and insightful case-studies. We emphasise that solutions to complex problems such as global ocean literacy demand the integration of multiple stakeholders and influence groups, across scales of time, space, organisation and society (McCauley et al. 2019). Building on this, we identify how drivers of ocean literacy can guide 'pathways to action', which we propose can improve global ocean literacy over the UN Decade of Ocean Science for Sustainable Development 2021-2030. In doing so, we generate an ocean literacy toolkit, a practical broad-focus resource for those working to enhance ocean learning and literacy worldwide.

\section{Research approach}

The methodological approach of this research is outlined in explicit detail in Nash et al. (2021). As with the other contributions to this Special Issue, this paper emerged as an interdisciplinary marine collaboration (i.e. marine ecology, marine socio-ecology, oceans policy, marine social science, climate impacts, ecosystem modelling, oceanography, environmental communications, psychology, philosophy, public health, maritime logistics and transdisciplinary science), that was facilitated through a series of expert workshops held in Hobart, Tasmania in 2018 and 2019. The aim of this specific collaboration was to synthesise existing knowledge and perspectives on ocean literacy from a range of disciplines and sectors, and through this synergy, outline a practical approach for furthering and improving ocean literacy to positively impact ocean use and sustainability.

This paper was initiated and developed over the series of workshops, which allowed us to bring our collectively broad range of perspectives and skills together to develop a more informed approach to understanding and improving ocean literacy than could have been achieved by one discipline or perspective. The resulting process of discussion, learning and exploration revealed our many disciplinary differences and entrenched understandings of (i) the ocean and (ii) the research process. These disciplinary tensions demanded time and space to create a 'shared language' and develop trust between members of our interdisciplinary team (i.e. Kelly et al. 2019), however they also fostered the fruitful conversations and discoveries that allowed us to identify and develop our vision towards a 'Sustainable 2030'. The discussions and resulting outcomes of each workshop were captured in meeting minutes and working documents, developed by the co-author team (predominately remotely and online) in between workshop events. The process and results of each workshop changed our understanding and direction as new knowledge, perspectives and research were revealed. In doing so, we developed a 'toolkit' for progressing ocean literacy.

To begin with, we identified a set of drivers that can be harnessed to achieve enhanced outcomes for ocean literacy, before establishing the pathways through which these drivers can guide positive action on ocean literacy. Following this, we identified (potential) limitations to developing and enhancing ocean literacy. Discussions on the limitations emerged as coauthors considered their own experiences in (and knowledge of) engaging with ocean literacy research and practice, in combination with limitations highlighted in the scientific literature. In particular, we identified potential barriers and challenges to developing ocean literacy interventions and activities, considering factors including social inequalities, 
diverse worldviews, evolving science, and sustainable development.

Building on knowledge from ocean literacy theory and practice, we established an ocean literacy toolkit (Appendix B) founded upon the key drivers, with the aim to equip the end-user with approaches to overcome limitations to developing ocean literacy. In doing so, we consolidated a three-phase approach to progressing ocean literacy that can facilitate behavioural change as a pathway to achieving a sustainable future. This phased approach is central to building a sound understanding of the diverse approaches available for increasing ocean literacy, as well as ensuring that the toolkit can be useful and accessible to a range of end-users (i.e. communities, educators, managers, and policy-makers). The applicability of the ocean literacy toolkit is illustrated by our provision of examples of diverse existing ocean literacy initiatives. The toolkit is presented as a framework to engage a range of diverse communities with (and in learning about) ocean issues.

\section{Drivers of ocean literacy}

In this section, we elucidate the four key drivers identified as necessary to achieve public connection to the ocean and improved ocean literacy globally:

1. Education,

2. Cultural connections,

3. Technological developments, and

4. Knowledge exchange and science-policy interconnections.

These drivers emerged as the result of a series of interdisciplinary workshops that were facilitated as part of the Future Seas project. The co-authors engaged in discussions (that were centred around disciplinary expertise and existing literature) to codefine (current and future) drivers of ocean literacy, based on author expertise and experience and literature; see Nash et al. (2021) in this Special Issue for more detail.

\section{Education}

Global education is key for achieving the SDGs, particularly in the context of the objectives of Goal \#14 (i.e. 'conserve and sustainably use the oceans, seas and marine resources for sustainable development').
Educational frameworks demonstrate that learning tends to be cumulative, gained via myriad experiences that include formal education in schools, universities and research institutions, as well as informal experiential learning. The latter includes learning provided by citizen science programmes, museums, zoos and aquariums (e.g. Monterey Bay Aquarium), exhibitions (e.g. SeaWalls by the Pangeaseed Foundation), recreation (e.g. experiential learning through fishing, diving, etc.), and media including film (e.g. Finding Nemo), television (BBC's Blue Planet), books, newspapers, magazines and the internet (e.g. social media and online games) (Dierking et al. 2003).

Initiatives that regularly bring informal and formal educational approaches together, such as science learning events (e.g. annual science weeks), provide foundational science-based information and new scientific knowledge to the public. These events can engage people with current knowledge and facilitate the exchange of new concepts and knowledge on shorter timeframes than formal curricula-based learning alone (Schmidt and Kelter 2017; Koomen et al. 2018). For example, the Australian National Science Week provides opportunity for Australian society to engage in formal science and informal learning. Over 1000 events are hosted and delivered by universities, schools, research institutions, libraries, museums and science centres around Australia each year, attracting more than a million people, including children and adults, science amateurs, and professionals. Similar science education initiatives are held in other countries (e.g. Science Week Ireland, Primary Science Week New Zealand, India's National Science Day), with the shared objective of inspiring people to learn and increase their participation in, and understanding of, science.

Experiential forms of learning have become of increasing interest and relevance to ocean learning in recent years (Jose et al. 2017; Owens 2018). Markedly, educators and science communicators are moving from older models of learning such as the 'knowledge deficit model' approach (i.e. which assumes that oneway communication of information infers uptake and application of such information) implicit in traditional approaches to ocean (science) learning (Hecker et al. 2018), to recognise alternative community understandings and epistemologies and their role in informing and supporting (science) learning (NASEM 2018). Whilst the value of experiential learning in an ocean 
literacy context has not been explicitly assessed to date, such forms of learning and connecting are evidenced to improve knowledge and skills, and enable positive connections and attitudes towards ocean environments to be developed (Dublickas and Ilich 2017).

Citizen science is a form of informal and (potentially) experiential learning, as participants learn via engaging in science activities (Crall et al. 2012) and knowledge-sharing (Nursey-Bray et al. 2018; Pecl et al. 2019). Citizen science, particularly marinefocused programmes, has expanded in scope and scale in recent years (Roy et al. 2012; Hyder et al. 2015; Nursey-Bray et al. 2018; Kelly et al. 2020). Citizen science has been identified as an effective and rigorous method for advancing marine conservation and improving management (Cigliano et al. 2015) by enhancing public engagement (Danielsen et al. 2014). As a result, multiple formal organisations have been established around the world to foster linkages between science and society, with a focus on addressing shared concerns and issues through science-based approaches (e.g. Citizen Science Association USA, Australian Citizen Science Association, Citizen Science Asia, European Citizen Science Association) (Shirk and Bonney 2015). Participation in citizen science connects people to natural environments including the ocean (Forrester et al. 2017), increases their concern for conservation issues (Johnson et al. 2014; Nursey-Bray et al. 2018), and can provide opportunities for communities to contribute to addressing these issues (Danielsen et al. 2014). As such, designing citizen science programmes to improve awareness and capacity to advocate for ocean environments (Ellwood et al. 2017) and solutions to ocean issues, can play a key role in engaging communities and increasing ocean literacy.

\section{Cultural connections}

Local and traditional knowledge can play a critical role in retaining understanding of the ocean within and amongst communities, and is increasingly being recognised as an important component of ocean literacy initiatives (Ford et al. 2016; Santoro et al. 2017; David-Chavez and Gavin 2018; IPCC 2019). In the Arctic, for example, Indigenous knowledge is widely included in community-based research and work partnerships conducted with government and other groups (Ford et al. 2015). An example of use of such knowledge is the observations of traditional fishers in the Baltic Sea, who reported the first records of blind Baltic Herring to local researchers in 2016. The researchers then linked the incidences of blindness to waste water from a new industrial plant in the area (Mustonen 2019). In Australia, Indigenous communities in the Torres Strait documented regular inundation of coastal areas during high tide associated with a tropical cyclone; a phenomenon that had not been observed in their traditional ecological knowledge system since the 1940s. Despite limited 'scientific' observational data on the inundation of the islands, the traditional communities' knowledge provided vital information that informed authorities and communities of the need to move further inland and raise the height-level of housing and settlements (Green 2006).

Historic intergenerational interactions with the ocean inform modern cultural identity, social values, and knowledge and practices, and continue to influence ocean literacy as cultural relationships with the ocean change and evolve (UNESCO 2009). For example, many traditional connections are shared and developed across artistic practices such as music, dance, poetry, sculpture, painting, film, theatre, literature, local social traditions, religion and mythology (Zurba and Berkes 2014; Hobart 2019). Oral traditions, in particular, play a central role in the intergenerational exchange of cultural knowledge about oceans and coasts and are re-emerging in recognition of the need for assessments of biodiversity, natural resources and climate change (Mustonen 2019); for example, Indigenous Australian communities have transferred climate records from generation to generation through their traditional 'dreamtime stories' (Roos 2013). Traditional marine communities belong to cultures where social identities and ways of life (including geography, culture and wildlife) are aligned to the sea (Song et al. 2019).

The transfer and sharing of traditional knowledge and practices between groups and generations are also lessons of experiential learning. Creating exchanges and relationships where learners can see and value their own experiences and understandings of resources is associated with increased persistence to learn and connect with these topics (Brossard et al. 2005), with considerable benefit for communities and researchers alike. For example, the North Australian Indigenous 
Land and Sea Management Alliance (NAILSMA) uses land and sea management-based activities as a focused engagement tool to achieve improved community learning, literacy and higher education by articulating the strong traditional links of Indigenous culture with existing communities' value and connection to the environment.

The benefits and experiences people derive from marine environments over periods of time build a fundamental sense of place, or deep-seated emotional bond with specific places and/or activities, thereby influencing environmental behaviours that can be regarded as cultural values (van Putten et al. 2018). Developments in the emerging field of neuro-conservation have demonstrated that being near the ocean can foster strong emotional interest in marine environments, and also improve personal well-being (Nichols 2014). For example, ocean-centred sports including surfing, diving, and sailing, create experiential learning opportunities that can engender strong connections to oceans (Lazarow et al. 2008; Nichols 2014). Further, these ocean sports and related subcultures have been demonstrated to influence behaviours that can support sustainable ocean use and generate personal attachment to the marine environment (Wiener et al. 2016).

Place-based attachment is a component of sense of place and infers that people who develop deep attachments and/or strongly identify with a place (i.e. a marine environment) will consider the interests of that place beyond their own interests (Brown and Raymond 2007). For example, local peoples' attachment to place has been shown to positively influence their engagement in environmentally friendly behaviour (Song et al. 2019). However, because sense of place is often intrinsically linked to cultural identity via history, social connections and personal understandings (Ryfield et al. 2019; Song et al. 2019), it can be a difficult feeling to articulate and quantify. Metrics of sense of place associated with marine environments are slowly being developed to better incorporate cultural values into marine management (van Putten et al. 2018).

\section{Technological developments}

In modern society, technologies (including web-based resources) are used by up to $95 \%$ of the population in countries worldwide (worldbank.org; ITU 2019). The number of mobile devices (including smartphones and tablets) has now exceeded the world's human population (to an estimated 7.22 billion devices in 2016) (Laranjo et al. 2015; Poushter 2016). It is anticipated that over $75 \%$ of the global population will have access to a smartphone device by 2025 (GSMA 2018). Increasing access to technology and the internet is likely to increase opportunities to engage and connect people to ocean issues on digital platforms. Information and communication technologies have become increasingly integrated across all sectors of society (Silverstone 2017). These emerging technologies have huge potential for engaging and educating groups about the ocean and in particular, for sharing and developing ocean knowledge; e.g., online resources can further current engagement and education activities (Benway et al. 2019; Moltmann et al. 2019).

Technology facilitates improved learning pathways by providing engaging and emotional experiences (Lee et al. 2013) that can reach targeted audiences from local to global scales. Technology-enabled resources are shown to successfully improve science and ocean literacy via an increasing number of online games and learning tools targeted across a range of age groups, and available on websites and smartphone platforms (Wu and Lee 2015; Brennan et al. 2019). The use of educational videos and games has been demonstrated to improve understanding of the causes and impacts of marine issues. For example, Medema et al. (2019) reported that many organisations concerned with sustainability and marine environments have begun to develop games with persuasive or learning messages, and that these games can prepare (and potentially incentivise) the changes urgently needed to address current and emerging environmental issues.

In an ocean literacy context, technology can assist in increasing environmentally-friendly behaviours; for example, improving youth understanding and resulting behaviour change in regards to marine plastic (Schoedinger et al. 2005; Hartley et al. 2015). Science agencies and communicators are producing more online content to distil complex science into understandable information that can be broadly used by wider society; e.g., via online magazines (e.g. Hakai, SEVENSEAS and ECOS magazines), podcasts (e.g. the NOAA ocean podcast, Beyond Penguins, OCTO$P O D$ ), videos (e.g. the Fisheye Project, the Australian Bureau of Meteorology's Climate Outlooks), and 
associated social media threads (e.g. see Kopke et al. 2019).

Still, technology is not a panacea for improving engagement and access to ocean learning and experiences (Lahoz-Monfort et al. 2019). Virtual experiences of nature do not elicit the same sensory stimulations and responses as real experiences (Truong and Clayton 2020), and thus influence how people (can) emotionally connect to the ocean and adopt associated pro-environmental behaviours. Furthermore, internet technologies now provide opportunities for ready distribution of false, adulterated or misreported information (i.e. 'fake news') and as a result, partisan and opinionated reporting has proliferated (Milhailidis and Viotty 2017; Barton 2019). Support for the maintenance and distribution of this partisan information is driven by multiple societal factors (Lewandowsky et al. 2017; Scheufele and Krause 2019), with some age groups particularly prone. For example, people over the ages of 65 are six times more likely to share incorrect and misleading information on internet sites than other age groups (Guess et al. 2019). Despite this, technological advancements and enhanced access to technologies potentially provide many innovative pathways for furthering ocean literacy, particularly at scale.

\section{Knowledge exchange and science-policy interconnections}

The aim of increasing ocean literacy requires that learning should not only be integrated into educational tools and curricula, but also in policy development (Costa and Caldeira 2018). When developing policies that might have an influence on the environment, policy-makers are tasked with the complex mission of balancing public perceptions, needs and values with multiple human activities, in order to develop the legislative infrastructure that can support and regulate those activities. In doing so, policy-makers are expected to develop policy principles and operational procedures based on the best available information. Thus, scientific outputs need to be communicated in formats that are accessible to policy makers, to ensure that new ocean policies are founded upon current knowledge and evidence (Bayliss-Brown and Ní Cheallacháin 2016; Fernández Otero et al. 2019) and that policy makers are aware of the need to incorporate those outputs. As such, marine science outputs are critical for informing a range of regional and international legal and policy developments that address key issues including climate change, marine conservation and the sustainable use of marine areas (e.g. areas beyond national jurisdiction), as well as for achieving and assessing existing policy directives (e.g. the EU's Marine Strategy Framework Directive) (Fernández Otero et al. 2019). However, in reality, the sciencepolicy process is complex and messy (Evans et al. 2017), limited by multiple barriers that include the disconnect between science and policy time-scales (i.e. short-term policy agendas versus need for longterm conservation agendas), poor engagement between science and policy-makers, and the fact that marine issues are multi-faceted, complex and uncertain (Walsh et al. 2019).

The urgency of action required to address current ocean issues renders it necessary to make existing resources and knowledge available (Fernández Otero et al. 2019), and emphasises the need for (i) effective knowledge exchange (i.e. with and between science, industry, policy and communities) (Cvitanovic et al. 2015), and (ii) increasing opportunity for knowledge co-production (Meadow et al. 2015), particularly at the science-policy interface. When facilitated successfully, knowledge exchange increases the likelihood that knowledge and evidence can be used in policy and that knowledge created is relevant to policy. This then increases the likelihood of those policy interventions achieving their objectives (Cash et al. 2003; Cvitanovic et al. 2015). For example, the EU-funded EKLIPSE project (https://www.eklipsemechanism.eu/) is an innovative initiative that brings science, policy, and stakeholders together to develop linkages between actors, to ensure that environmental decisions made within the EU are based on 'best available knowledge'. The project has a long-term goal of sustaining these linkages and exchange. It also seeks to develop a support mechanism for cooperation that can identify research priorities, enable knowledge transfer and synthesis, and support new networks that can enhance environmental research and decisionmaking into the future. Similarly, the science-led initiative 'Consensus for Action' is enabling scientists to communicate the significance of environmental issues to policy-makers worldwide, providing them with accessible and digestible knowledge from leading science research on pertinent global issues (e.g. climate change, ecosystem loss, pollution and population 
growth) (Barnosky et al. 2016). The initiative is also working to connect with communities and equip them with a platform to voice their need for policy-makers to take action. When knowledge exchange is one-way or infrequent or fails to be inclusive of all stakeholders, the effective use of knowledge is compromised; science is often focused on yesterday's problems (thereby producing non-salient information), or decision-making is done with yesterday's knowledge (therefore is based on information that may not be relevant) (Cash et al. 2003).

Knowledge co-production infers that decisionmakers (and other actors) actively collaborate with scientific research projects from inception and development, and also participate and contribute to the project implementation and delivery (including design, implementation and analysis) (Norström et al. 2020). Successful co-produced science initiatives demonstrate the value of such approaches, particularly in achieving equitable and sustainable project and policy outcomes. For example, in the case of a mussel fishery in the Dutch Wadden Sea, knowledge co-production between resource users, science and policy led to a shared knowledge-base and improved governance of the fishery, which helped to stabilise conflict and controversy associated with the fishery (van der Molen et al. 2015). In Scotland, the Community of Arran Seabed Trust (COAST) initiative established a community-led ecosystem research programme that provided the impetus for further scientific monitoring, and eventually resulted in a collaborative community, science and policy effort to designate 30 marine protected areas in Scottish Waters (Stewart et al. 2020). Training opportunities for scientists to engage with policy (e.g. through schemes such as the Australian Academy of Science Annual Sciencepolicy Internship) are needed to equip (particularly early-career) researchers with the skills, knowledge, and perspectives necessary to successfully create coproduced knowledge and outputs with policy and other actors (Evans and Cvitanovic 2018).

\section{Moving beyond 'business as usual' to a sustainable 2030 - a toolkit for ocean literacy}

A succinct guide for achieving ocean literacy is required in order to understand how levels of ocean literacy can increase over time. Considering these limitations, and in recognition of the vast potential for improving global ocean literacy during the UN Decade of Ocean Science for Sustainable Development 2021-2030, here we develop a toolkit for ocean literacy (see Appendix B). The ocean literacy toolkit brings together theoretical approaches to learning, frameworks for understanding target communities and assessing ocean literacy activities/interventions, as well as practical examples of existing techniques and ocean literacy activities/interventions, with an aim to reduce current gaps between science and public understanding of science, and guide increased ocean literacy across society.

First, the toolkit presents 'ten best practice principles for environmental learning' - considerations for those wishing to design and implement an ocean literacy activity/intervention. Second, the toolkit introduces an activity/intervention design and implementation framework that draws on Bloom's Taxonomy (Bloom et al. 1956; Anderson et al. 2001) as a pathway for learning and evaluation, and employs the Seven Principles of Ocean Literacy outlined in (Santoro et al. 2017), following (Cava et al. 2005) as a focus for that learning. This framework identifies key stages for action grouped under two phases and delineates how ocean literacy activities/interventions can be implemented in practice, including identifying communities that might benefit and the specific issues an activity/intervention might be directed towards. Last, the toolkit highlights examples of diverse activities/interventions currently being successfully implemented to achieve ocean literacy in myriad contexts (e.g. small and large scale, experiential learning, multiple age-groups, technological/digital, etc.). When ocean literacy initiatives are tailored to relevant issues and communities, they increase knowledge uptake and engender attitudes of concern that can promote personal action (Ashley et al. 2019).

As outlined and discussed in this paper, the concept of ocean literacy continues to evolve as new ocean literacy initiatives and approaches (including technologies; see Appendix A) are continually being developed (UN 2018a; Ashley et al. 2019). As of 2020, public involvement in citizen science is growing, and wide-reaching media campaigns (e.g., \#PlasticFree, \#Take3ForTheSea) and documentaries (e.g., the BBC's Blue Planet 2) are educating and encouraging diverse communities to engage in ocean-friendly behaviours. Recognition of traditional knowledge and 
the importance of cultural connections is increasing (Kikiloi et al. 2017). Thus, it is likely that a 'business as usual' trajectory will still achieve some positive change in the field of ocean literacy, with potential for substantive change in some instances. However, limitations to the current trajectory and areas in which increased efforts are required are apparent when we consider the scale at which ocean literacy will need to increase in order to meet the goals set by the UN 2030 Agenda.

In this section, we highlight five main limitations that are currently impeding the potential development and improvement of global ocean literacy:

1. Youth-centric ocean learning,

2. Western-centric programmes,

3. Single-issue focus,

4. The 'digital divide', and

5. Disconnect between society and marine science and policy.

We emphasise, however, that these limitations are not all encompassing and that they can largely be addressed or at least, reduced, by harnessing approaches which reflect the drivers of ocean literacy. Linking to the ocean literacy toolkit (Appendix B), below we detail how the drivers of ocean literacy can be harnessed to achieve enhanced outcomes overall. Below, we identify examples and pathways to overcoming the limitations, to demonstrate how the application of the drivers can be facilitated in practice. The principles and initiatives identified in the toolkit are not intended to be exhaustive, but rather provide examples of transformational ways through which each of the four drivers can be engaged to address limitations and barriers to ocean literacy, and facilitate improved ocean literacy, in support of achieving a 'Sustainable 2030' as envisaged under the UN 2030 Agenda and the Future Seas project.

\section{Impediment 1: youth-centric ocean learning}

Youth ocean literacy is perceived to be increasing (e.g. Lee et al. 2019), largely as a result of ocean literacy curricula being adopted in some schools and youth groups in some regions around the world (Fauville et al. 2018a). However, opportunities for other groups in society to engage with ocean literacy are less prevalent (Fernández Otero et al. 2019). This is particularly problematic when considering that youth are most likely to be excluded from decision-making processes (Gal 2017; Botchwey et al. 2019). It is typically adults who engage in decisions that impact the ocean (e.g., choosing between sustainable versus unsustainable seafood or between disposable versus reusable/recycled products, etc.) and who potentially have the power to drive current change through voting behaviour, placing lobbying pressure on government actors and their involvement in decision making processes (Vromen and Colin 2010; Gal 2017). There is a critical need for approaches that can target and improve ocean literacy across all components of society. Improving opportunities for ocean learning requires better access to comprehensive, deep-level learning across all age groups and across all of society, including in particular those with limited access to the ocean (i.e. disadvantaged and/or landlocked communities). This learning is unlikely to be achieved through curricula and formal learning activities alone.

Engagement in ocean-centred activities (i.e. fishing, sailing, beach-going, etc.) provides experiential learning opportunities that can engender positive social experiences, deeper personal connections to the ocean, and stronger place attachments that enhance understanding and appreciation of the marine environment (Principles 4, 6; Examples 3, 9, 13) (Ainsworth et al. 2019). Emerging research suggests that positive people-place relationships can also be fostered without direct personal experience of a marine environment. This research might provide means to (re)develop connections with urban or land-locked populations and improve their knowledge of the ocean (Examples 4, 6, 8). For example, (Gurney et al. 2017) demonstrated that cultural connections can be developed beyond conventional expectations, and that connections to place (e.g. Great Barrier Reef) can be developed without physically visiting that environment. Similarly, 'blue space' initiatives have led to applied community-centred approaches to improving awareness and connection to marine environments amongst urban populations (Gascon et al. 2017; Garrett et al. 2019). Experiential approaches, including the development of 'city marine parks', specifically aim to engage urban citizens with the marine environment in order to improve their understanding of the ocean, foster feelings of connectedness and stewardship, and promote cultures of urban marine citizenship (Principle 8) (Pittman et al. 2019), thereby 
engaging groups of society who otherwise would have no exposure to ocean literacy learning.

Furthermore, media dialogue can be employed to increase ocean literacy amongst a wider population (Examples 1, 5). Plastic pollution, in particular, is a marine issue that has gained attention across the planet. For example, in 2015, Henderson Island in the South Pacific made headlines as 'the most polluted place on the planet ${ }^{1}$ this media uptake significantly piqued public awareness of ocean plastic pollution and the island was subsequently extensively studied by scientists (Lavers and Bond 2017; Serra-Gonçalves et al. 2019). This media and resulting public interest in Henderson Island, and other instances of research and media communicating the effects of ocean plastic pollution around the world (Beaumont et al. 2019; Gibbs et al. 2019; van der Mheen et al. 2019), demonstrate the speed at which ocean knowledge can be shared with society, thereby increasing public understanding of emerging and relevant marine issues and research (Principle 9) and marine stewardship. This rapid uptake is exemplified by how different organisations have begun to incorporate sustainable and recycled plastic manufacturing as a key point-ofdifference in their marketing narrative (e.g., businesses such as 4Ocean, Elvis \& Kresse, Mós, etc.)

\section{Impediment 2: western-centric programmes}

Most recent developments in the ocean literacy movement have been achieved and implemented in Western, and predominately English-speaking, countries (for case examples, see Fauville et al. 2018a). Whilst numerous educational programmes and platforms have been implemented with the aim of widespread use, the uptake of these programmes beyond western and predominantly English-speaking platforms is limited by (i) the capacity for integration into national curricula (Blum et al. 2013; Gough 2017; McPherson et al. 2018; Wulff and Johannesson 2019), (ii) the lack of financial and institutional support,

\footnotetext{
- https://www.nationalgeographic.com/news/2017/05/hendersonisland-pitcairn-trash-plastic-pollution/

- https://www.abc.net.au/news/science/2017-05-16/plasticpollution-on-henderson-island-in-south-pacific/8527370

- https://www.theguardian.com/environment/2017/may/15/ 38-million-pieces-of-plastic-waste-found-on-uninhabitedsouth-pacific-island
}

particularly in developing countries (de Gusmão Pedrini et al. 2019), (iii) regional variability in access to technology, particularly in the context of developed versus developing countries (Poushter 2016), (iv) the capacity for transitioning from content-based to more transformative (and potentially digital) learning curricula (Bangay and Blum 2010; Leicht et al. 2018), and (v) the availability of educational content that can be tailored to local contexts and languages (and narratives) and can enable meaningful connections that are representative of communities (e.g. Lee et al. 2019). There is a need to develop and implement ocean literacy programmes that are inclusive of local contexts and culture, as well as to improve the associated capacity to deliver and improve ocean literacy across regions, languages and cultures in the long-term.

Respectful inclusion of local and traditional knowledge can enhance modern approaches to understanding the marine environment by providing a holistic perspective, and facilitating cultural connections and ocean literacy (Principle 1) (Kikiloi et al. 2017). Today, cultural values, knowledge, and approaches to using marine environments are increasingly being recognised and incorporated into regional marine management (Example 12) (Fulton et al. 2011; Kikiloi et al. 2017; McKinley et al. 2019). Integration of traditional knowledge and methods are also enabling more socially accepted and environmentally sustainable outcomes (Principles 2, 7, 8); e.g., sea country in Tasmania (TebrakunnaCountry and Lee 2019); ra'ui amongst Polynesian cultures (Aburto et al. 2015); Sgeulachdan na Mara ('Sea Stories') in Scotland (Example 14) (Brennan 2018), and Navigating Change in Hawaii (NOAA 2019). Furthermore, disconnected or displaced local communities are increasingly reconnecting with their traditional places and practices; for example, in 2019, the traditional Heiltsuk community in Canada were successful in reinstating a traditional ' $\lambda$ iác'i (or 'big house' - a customary space for acts of governance and ceremony). This cultural resurgence is enabling communities to revive their knowledge sharing and ocean practices, with growing interest and potential to share and communicate this knowledge with wider society.

Indigenous/Community Conserved Areas (ICCAs) are a successful example of interactive collaboration between contemporary governance models and traditional knowledge systems. For example, traditional knowledge of the sea (i.e., traditional ocean literacy) is 
now being used to conserve the environmental values of the seas surrounding Coron Island in the Philippines and has become central to the management of the Coron Island ICCA (Sampang 2005; Kothari 2008). In Fiji, community-based resource management is a dynamic system of social interventions, shaped by local practices and influenced by a combination of internal and external events. Indigenous Fijian (iTaukei) communities hold customary marine tenure over Fiji's inshore waters, and continue to use traditional knowledge to harvest and manage these marine resources (Principles 4, 8); (Sloan and Chand 2016). Customary practices are the basis of community-based resource management activities and encourage groups to better understand both the influence of cultural roles on the effectives of local marine management areas, and how traditional practices can address the challenges faced today and into the future (Principle 10).

\section{Impediment 3: single-issue focus}

Increased public attention on trending issues such as the plastic pollution crisis has resulted in reduced market demand for plastic products (Locock et al. 2017) and policy change (e.g. EU plastic ban by 2025), with flow-on benefits for the environment including reducing sources of plastic inputs into the ocean. Given the complexity of marine environments, and the number of stressors impacting the ocean, such singleissue focus can assist in simplifying complexities for broader audiences and avoid overwhelming audiences to the point of disengagement. However, a single-issue focus overlooks other stressors impacting the ocean (e.g. overfishing, climate change, habitat loss, invasive species, and pollution) and the need for integrated changes that can provide for the mitigation of these (Stafford and Jones 2019). Ocean literacy initiatives should be focused around integrated approaches that combine knowledge types and communication strategies to provide holistic understanding of issues and engage communities in sustainable approaches to marine resource use and management (Fletcher et al. 2009; Vince and Hardesty 2016).

As highlighted above, traditional knowledge systems provide holistic perspectives on marine systems and can provide alternative approaches to enhancing ocean literacy (Kikiloi et al. 2017). They also offer a perspective that allows for the acknowledgement of multiple issues and consideration of alternative approaches that can be integrated in addressing ocean issues. In many instances, traditional knowledge systems are based on valuing the relationship individuals have with their environment; decisions and behaviours associated with local ecology (i.e. the natural resources and environments communities interact with) are reflective of community perceptions of themselves, in relation to their surrounding environments (Principles 3, 7) (Berkes et al. 1994). Amongst Western communities, studies have identified that individuals primarily source information about the ocean from television and the internet (Gelcich et al. 2014). There is therefore a need for information provided via such platforms to extend reporting beyond single issues and adopt more integrated and holistic reporting of ocean issues, and also solutions being developed to address them (Examples $2,8,17)$, if wider community ocean literacy and stewardship are to be achieved.

Furthermore, as evidenced by the plastic pollution crisis, over-simplification of an issue can also result in solutions being over-simplified. Most public awareness and action on plastic pollution mitigation centres around pushing for the use of reusable utensils (e.g. 'keepcups'), promoting beach clean-ups, or publicising new technological solutions to 'clean up the ocean' (Stafford and Jones 2019). Whilst these technological solutions are well-intended to reduce pollution in the ocean, they distract from the root cause of this pollution; over-reliance on (and poor disposal of) plastic-packaged products, and environmentally-damaging fishing practices (Li et al. 2016). Addressing this problem of plastic pollution, and other wicked problems such as climate change, demands major changes to human behaviour (Principle 7) (Eagle et al. 2016), (which can be supported by improving ocean literacy to inform and encourage (more realistic) oceanfriendly behaviours (Principle 6) (Cash et al. 2003; Ashley et al. 2019; Fernández Otero et al. 2019).

\section{Impediment 4: the digital divide}

Increasing reliance on technology for engaging and teaching people about the ocean (particularly in the current COVID-19 climate) is likely to widen existing knowledge gaps between digitally-divided groups. Thus, enabling wider uptake and availability will be crucial in maximising the utility of technology as a key driver for achieving ocean literacy and the broader 
objectives of SDG \#14 (Lahoz-Monfort et al. 2019). It should be noted, however, that society exhibits varying levels of trust in the information that is provided to them via digital platforms. Research has documented that communities place their greatest trust in scientific outcomes (i.e. reports and journal publications) (Gelcich et al. 2014), highlighting the need to increase the accessibility of easily digestible and upto-date scientific outputs (Principle 9). One example of successful scientific knowledge sharing is The Conversation (https://theconversation.com/), an Australian-led online journal initiative that publishes publicly-accessible articles on the research behind current and emerging topics of regional relevance. The journal network now extends across several regional chapters (and also provides global perspectives) that provide a journalistic format for society to access current science (Zardo et al. 2018).

The use of technology has significant potential to enhance sharing and uptake of comprehensible information about the ocean (Examples 4, 5, 11, 14). For example, as smartphones continue to evolve, they are increasingly enabling access to technology and the internet, which historically have been restricted in many societies around the world. However, despite the increasing availability of modern technologies described above, many regions and demographics still lack access to (or choose not to use) technology. This resulting digital divide (i.e. the gap between those with access to technology and those without) is influenced by multiple factors, including socio-economics, age, gender, tech-literacy and social licence (Laranjo et al. 2015; Poushter 2016; UN 2019a). Technological literacy (i.e. knowledge about technology, and the ability to learn and develop skills that maximise opportunities provided by technology) is a limitation that particularly drives the digital divide in more developed nations; where lower-income, lesser educated, unemployed, rural and older populations have limited access and opportunity to engage in learning about digital technologies (Montagnier and Wirthmann 2011; Poushter 2016) and therefore have limited access to learning experiences provided through these platforms. Technological infrastructure also plays a role in determining how technology is shared, accessed, adopted and developed. In particular, internet access is the primary factor driving the global digital divide. It is estimated that more than $75 \%$ of populations in low and middle income countries do not have regular access to internet (Poushter 2016) although as highlighted above, this is changing.

Many initiatives are already addressing the digital divide in practice. For example, in the Western Indian Ocean region, the SOLSTICE Project (Sustainable Oceans, Livelihoods and food Security through Increased Capacity in Ecosystems) aims to improve the quantity and quality of data collected in the Western Indian Ocean by providing local training and access to technological equipment (Principle 6). The project is working to increase knowledge transfer and uptake by employing low-cost technologies (e.g., numerical models, satellite data, autonomous robotics) to cheaply and efficiently generate environmental data in real-time. Whilst the primary end-users of this knowledge transfer initiative are policy-makers and marine managers, components of the project also engage the wider community in ocean learning via outreach activities including educational online videos and a massive open online course (MOOC). Another example of tech use for furthering ocean literacy is the Australian Ocean Lab (AusOcean), a non-governmental organisation that uses open-source technology to engage and educate children about the ocean. Their project Network Blue engages with school-age students to collaboratively construct, deploy, and maintain floating ocean monitoring stations which provide data to a growing citizen science project network (Principles 2,6). The design of this project -i.e. use of low-cost, widely-accessible technology (an opensource microcontroller) and materials (PVC pipe), and freely available assemblage instructions - has increased opportunity for its uptake as an educational and scientific activity that could also potentially engage other groups in experiential citizen science learning.

Impediment 5: disconnect between society and marine science and policy

To date, the ocean literacy movement has primarily been driven by scientists and educators whose work is associated with marine science (Kopke et al. 2019). However, as outlined above, ocean literacy is a challenge and opportunity for all parts of society, including educators, children and adults, wider community groups, scientists, consumers and policy/ decision makers (Borja et al. 2020), and there is a resulting need for more inclusive approaches to 
marine science and decision-making. Ocean literacy is founded upon knowledge sharing and learning and thus, relies on the communication of accessible and up-to-date marine science information (Principle 9). It is no longer enough to 'simply do the science and publish an academic paper' (Barnosky et al. 2016), and the science communication efforts and initiatives that many authors of this collaborative paper have contributed to (Example 5, 10, 12, 13, 16) exemplify the need and possibility of developing and sharing research further to achieve community and policy impact outside of 'the Ivory Tower' (Kelly et al. 2018). Scientists can also communicate research in indirect ways, such as supporting citizen science projects that increase community trust in science and conservation (Principles 2, 3) (Bonney et al. 2016; Kelly et al. 2019), engaging with remote learners in ocean-focused massive open online courses (MOOCs) (Fielding et al. 2019), or by collaborating with 'ocean champions', community leaders or celebrities who can deliver marine science messages to wider audiences (Principles 4, 8, 10; Examples 12, 13, 14) (Day 2017).

Optimistic messages and positive stories, in particular, encourage people to collaborate strategically in addressing pressing marine environmental problems (Principle 5). Optimism supports the personal and collective efficacy needed to instigate joint action for a cause (McAfee et al. 2019). However, such messages of hope risk diluting the urgency and extent of environmental problems (Hornsey and Fielding 2016) and (science) communicators and educators should ensure their optimistic messages are centred upon realism (Principle 9) (Cvitanovic and Hobday 2018). Thus, complex ocean issues are best communicated using interdisciplinary approaches, such as the Future Seas (https://futureseas2030.org/) initiative, that bring together natural scientists (e.g. ecologists, oceanographers) and social and behavioural scientists (e.g. sociologists, psychologists), as well as community stakeholders and traditional owners (Examples $12,13)$, to enhance the palatability and resonance of ocean science for communities and other marine stakeholders (Principle 8) (McAfee et al. 2019). Marine researchers, in particular, are often passionate workers in their fields who already act as advocates and educators without realising it (Parsons 2016). However, we note that scientists alone cannot be expected to communicate research and emerging ocean issues to society. Whilst engaging and learning from stakeholders can be a rewarding experience, it can also become time-consuming and resourcedraining (Illingworth 2017). Expanding collaborations to include professional science communicators, whose training and qualifications enable them to understand the needs and contexts of particular ocean issues as well as identify best means, to connect theses message to communities and stakeholders (Kelly et al. 2018).

Importantly, ocean literacy learning should be not only be integrated into educational programmes and curricula, but also in policy development (Costa and Caldeira 2018). Long-term sustainability for marine socio-ecological systems can be enhanced where decision-making processes recognise and incorporate multiple, diverse and often-conflicting values of the marine environment held by society, especially as excluded groups are likely to question the legitimacy of decisions they have not been party to deciding (Principles 3, 7, 8) (Cash et al. 2003). In order to achieve this, new pathways for open and trusted knowledge exchange are needed. Clarke and Flannery (2019) emphasise a need to i) empower stakeholders to produce and use different knowledge types (i.e. scientific, traditional, etc.; Principles 1, 2), and ii) improve capacities to engage stakeholders and communities in marine decision-making processes (Principles 6,8$)$. Meaningful interactions and participation in such dialogue (i.e. in contrast to one-way communication) encourage trust, collaboration, ownership and stewardship - all critical components of successful ocean (literacy) programmes (Examples, 10, 12, 13, 16) (Young et al. 2013; Bennett and Dearden 2014).

As we have documented, ocean literacy programmes are widespread and diverse and while they are likely to have shared goals, the ability to quantitatively measure progress in global ocean literacy is currently lacking. There is increasing recognition that universal processes for measuring the effectiveness of programmes are needed for making and tracking progress in ocean literacy (Fauville et al. 2018b). The toolkit has been intentionally created as a practical resource that can guide groups and communities working to implement contextual activities/interventions for improving ocean literacy across spatial and temporal scales and applicable in a broad range of contexts. How, and to what extent, the toolkit might be implemented will be dependent on those contexts, but the flexibility of the framework means that it is 
applicable and scalable, from small introductory initiatives through to formal widespread curricula. However, we note that paying attention to local and cultural contexts, and community interests and dynamics (i.e. practice principles) are key to informing and motivating the behaviour changes necessary to improve global ocean literacy. In doing so, we hope that practitioners and researchers can employ this toolkit using participatory, as well as inter- and transdisciplinary approaches that will foster partnerships and sustain networks of ocean learning and literacy. Finally, whilst technology is an increasing driver of ocean literacy with many benefits (Martin et al. 2020), we emphasise that technology alone will not connect people to the ocean (Truong and Clayton 2020). The four drivers-education, cultural connections, technological developments, knowledge exchange and science-policy interconnections-will achieve most impact when applied together in diverse engaging and innovative activities, as outlined in the toolkit. Connecting people to the ocean via diverse experiential learning and activities is central to engendering broadscale marine stewardship and normalising the behaviours needed to expand ocean literacy at a global scale (Stoll-Kleemann 2019).

\section{Conclusion}

Understanding the human-ocean connection and contributing positively to discussions about the future of the ocean demands a level of ocean literacy (Fauville et al. 2018b). Thus, an aim of improving global ocean literacy is to enhance societal understanding of ocean issues and capacity 'to make a difference' (Schubel and Schubel 2008). This paper highlights the growing movement (of research and practice) working to progress ocean literacy and identifies four key drivers through which this progression is likely to develop. These drivers - (1) education, (2) cultural connections, (3) technological developments, and (4) knowledge exchange and science-policy interconnections-will each play a key role in enhancing ocean literacy, but are likely to achieve a greater impact when combined with improved policy and political will (Stafford and Jones 2019). The implementation of policies that support the inclusion of ocean literacy curricula throughout formal educational pathways, formal processes for recognising, supporting and enhancing cultural connections to the ocean, as well as enhancing access to and uptake of technologies, are central for developing and supporting the ocean literacy movement in achieving sustained and positive behavioural change.

The toolkit highlights that ocean literacy activities can be led by a broad range of stakeholders and benefit a wide variety of communities, societies and environments. The growing global ocean literacy movement is evolving into a network that can support new approaches for engaging communities and society on ocean issues. In this way, ocean literacy is a 'crosscutting' theme of the UN Decade of Ocean Science for Sustainable Development 2021-2030 that can contribute in a critical way to achieving the Decade's Societal Outcomes. The toolkit is designed to support this movement and its evolution, to further global ocean literacy in another step towards Sustainable 2030.

Acknowledgements This paper is part of the Future Seas project (futureseas2030.org), hosted by the Centre for Marine Socioecology at the University of Tasmania. This initiative delivers a series of journal articles addressing key challenges for the UN Decade of Ocean Science for Sustainable Development 2021-2030. The general concepts and methods applied in many of these papers were developed in large collaborative workshops involving more participants than listed as co-authors here, who we thank for their collective input. We acknowledge and pay respect to the traditional owners and custodians of sea country all around the world and recognise their collective wisdom and knowledge of our oceans and coasts. Funding for Future Seas was provided by the Centre for Marine Socioecology, IMAS, CSIRO, MENZIES and the College of Arts, Law and Education, and the College of Science and Engineering at UTAS, and Snowchange from Finland. We acknowledge support from a Research Enhancement Program grant from the DVCR Office at UTAS. A.M. acknowledges support from the ARC Centre of Excellence for Climate Extremes (CE170100023). GP was supported by An Australian Research Council Future Fellowship.

\section{References}

Aburto JA, Gaymer CF, Haoa S, González L (2015) Management of marine resources through a local governance perspective: re-implementation of traditions for marine resource recovery on Easter Island. Ocean Coast Manag 116:108-115

Ainsworth GB, Kenter JO, O'Connor S, Daunt F, Young JC (2019) A fulfilled human life: eliciting sense of place and cultural identity in two UK marine environments through the community voice method. EcosystServ 39:100992 
Anderson LW, Krathwohl DR, Airasian PW, Cruikshank KA, Mayer RE, Pintrich PR, Raths J, Wittrock MC (2001) A taxonomy for learning, teaching and assessing: a revision of bloom's taxonomy of educational objectives. Longman Press, New York

Ashley M, Pahl S, Glegg G, Fletcher S (2019) A change of mind: Applying social and behavioural research methods to the assessment of the effectiveness of ocean literacy initiatives. Front Mar Sci 6:288

Bamberg S, Moser G (2007) Twenty years after Hines, Hungerford and Tomera: a new meta-analysis of psychosocial determinants of pro-environmental behavior. J Environ Psychol 27:14-25

Bangay C, Blum N (2010) Education responses to climate change and quality: two parts of the same agenda? International J Educ Develop 30(4):359-368

Barnosky AD, Ehrlich PR, Hadly EA (2016) Avoiding collapse: grand challenges for science and society to solve by 2050 . ELEMENTA Sci Anthr 4:000094

Barton CC (2019) Critical literacy in the post-truth media landscape. Policy Futures in Educ 17:1024-1036

Basile S (2016) Cool: how air conditioning changed everything. Fordham University Press, New York, NY

Bayliss-Brown, G. A. and C. Ní Cheallacháin (2016). Knowledge transfer with EU-funded marine science research: A viewpoint. Geophysical Research Abstracts 18(EGU General Assembly 2016).

Beaumont NJ, Aanesen M, Austen MC, Borger T, Clark JR, Cole M, Hooper T, Lindeque PK, Pascoe C, Wyles KJ (2019) Global ecological, social and economic impacts of marine plastic. Mar Pollut Bull 142:189-195

Bennett NJ, Dearden P (2014) From measuring outcomes to providing inputs: governance, management and local development for more effective marine protected areas. Mar Policy 50:96-110

Benway HM, Lorenzoni L, White AE, Fiedler B, Levine NM, Nicholson DP, DeGrandpre MD, Sosik HM, Church MJ, O'Brien TD, Leinen M (2019) Ocean time series observations of changing marine ecosystems: an era of integration, synthesis and societal applications. Front Mar Sci 6:393

Berkes F, Folke C, Gadgil M (1994) Traditional ecological knowledge, biodiversity, resilience and sustainability. In: Perrings CA, Mäler KG, Folke C, Holling CS, Jansson BO (eds) Biodiversity Conservation. Kluwer, London

Bloom BS, Engelhart MD, Furst EJ, Hill WH, Krathwohl DR (1956) "Taxonomy of educational objectives: the classification of educational goals." Handbook 1: congnitive domain. David McKay Company, New York

Blum N, Nazir J, Breiting S, Goh KC, Pedretti E (2013) Balancing the tensions and meeting the conceptual challenges of education for sustainable development and climate change. Environ Educ Res 19(2):206-217

Bonney R, Phillips TB, Ballard HL, Enck JW (2016) Can citizen science enhance public understanding of science? Public Underst Sci 25:1-15

Borja A, Santoro F, Snowcroft G, Fletcher S, Strosser P (2020) Editorial: connecting people to their oceans: issues and options for effective ocean literacy. Front Mar Sci 6:837
Botchwey ND, Johnson N, O'Connell LK, Kim AJ (2019) Including youth in the ladder of citizen participation. J American Plan Assoc 85(3):255-270

Bratman GN, Anderson CB, Berman MG, Cochran B, deVries S, Flanders J, Folke C, Frumkin H, Gross JJ, Hartig T, Kahn PH (2019) Nature and mental health: an ecosystem service perspective. Sci Adv 5(7):0903

Brennan C, Ashley M, Molloy O (2019) A systems dynamic approach to increasing ocean literacy. Front Mar Sci 6:360

Brennan RE (2018) Re-storying marine conservation: Integrating art and science to explore and articulate ideas, visions and expressions of marine space. Ocean Coast Manag 162:110-126

Brossard D, Lewenstein BV, Bonney R (2005) Scientific knowledge and attitude change: the impact of a citizen science project. International J SciEduc 27(9):1099-1121

Brown G, Raymond CM (2007) The relationship between place attachment and landscape values: toward mapping place attachment. ApplGeogr 27:89-111

Cash DW, Clark WC, Alcock F, Dickson NM, Eckley N, Guston DH, Jäger J, Mitchell RB (2003) Knowledge systems for sustainable development. PNAS 100(14):8086-8091

Catalano AS, Lyons-White J, Mills M, Knight AT (2019) Learning from published project failures in conservation. Biol Cons 238:108223

Cava, F., S. Schoedinger, C. Strang and P. Tuddenham (2005). "Science content and standards for ocena literacy: A report on ocean literacy." National Marine Eductors Association Report.

Cigliano JA, Meyer R, Ballard HL, Freitag A, Phillips TB, Wasser A (2015) Making marine and coastal citizen science matter. Ocean Coast Manag 115:77-87

Clarke B, Stocker L, Coffey B, Leith P, Harvey N, Baldwin C, Baxter T, Bruekers G, DaneseGalano C, Good M, Haward M, Hofmeester C, De Freitas DM, Mumford T, NurseyBray M, Kriwoken LK, Shaw J, Shaw J, Smith T, Thomsen D, Wood D, Cannard T (2013) Enhancing the knowledgegovernance interface: coasts, cliamte and collaboration. Ocean Coast Manag 86(889):88-99

Clarke J, Flannery W (2019) The post-political nature of marine spatial planning and modalities for its re-politicisation. J Environ Policy Plan 22:170-183

Costa S, Caldeira R (2018) Bibliometric analysis of ocean literacy: an underrated term in the scientific literature. Mar Policy 87:149-157

Cox DT, Hudson HL, Shanahan DF, Fuller RA, Gaston KJ (2017) The rarity of direct experiences of nature in an urban environment. Landsc and Urb Plan 160:79-84

Crall AW, Jordan R, Holfelder K, Newman G, Graham J, Waller DM (2012) The impacts of an invasive species citizen science training program on participant attitudes, behaviour and science literacy. Public UnderstSci 22(6):745-764

Cvitanovic C, Hobday AJ (2018) Building optimism at the environmental science-policy-practice interface through the study of bright spots. Nat Commun 9:3466

Cvitanovic C, Hobday AJ, van Kerkhoff L, Wilson SK, Dobbs $\mathrm{K}$, Marshall NA (2015) Improving knowledge exchange among scientists and decision-makers to facilitate the adaptive governance of marine resources: a review of 
knowledge and research needs. Ocean Coast Manag 112:25-35

Danielsen F, Pirhofer-Walzl K, Adrian TP, Kapijimpanga DR, Burgess ND, Jensen PM, Bonney R, Funder M, Landa A, Levermann N, Madsen J (2014) Linking public participation in scientific research to the indicators and needs of international environmental agreements. Conserv Lett 7(1):12-24

David-Chavez DM, Gavin MC (2018) A global assessment of Indigenous community engagement in climate research. Environ Res Lett 13(12): 123005

Day JC (2017) Effective public participation is fundamental for marine conservation - lessons from a large-scale MPA. Coast Manag 45(6):470-486

de GusmãoPedrini A, Kremer LP, Brotto DS, da Silva VRF (2019) Emblematic coastal and marine environmental education projects in Brazil. In: Ghilardi-Lopes NP, Berchez FADS (eds) Coastal and Marine Environmental Education. Springer, Cham

Dierking LD, Falk JH, Rennie L, Anderson D, Ellenbogen K (2003) Policy statement of the 'informal science education' ad hoc committee. J Res Sci Teach 40:108-111

Duarte CM, Agusti S, Barbier E, Britten GL, Castilla JC, Gattuso J-P, Fulweiler RW, Hughes TP, Knowlton N, Lovelock CE, Lotze HK, Predragovic M, Poloczanska ES, Roberts C, Worm B (2020) Rebuilding marine life. Nature 580:39-51

Dublickas K, Ilich A (2017) Becoming an ocean advocate through experiential learning. Oceanography 30(4):10-11

Eagle L, Hamann M, Low DR (2016) The role of social marketing, marine turtles and sustainable tourism in reducing plastic pollution. Mar Pollut Bull 107:324-332

Ellwood ER, Crimmins TM, Miller-Rushing AJ (2017) Citizen science and conservation: recommendations for a rapidly moving field. Biol Cons 208:1-4

Evans MC, Cvitanovic C (2018) An introduction to achieving policy impact for early career researchers. Palgrave Commun 4:88

Evans MC, Davilla F, Toomey A, Wyborn C (2017) Embrace complexity to improve conservation decision-making. Nat Ecol and Evol 1:1588

Fauville G, Payne DL, Marrero ME, Lantz-Andersson A, Crouch F (2018) Exemplary practices in marine science education: a resource for practitioners and researchers. Springer, Cham

Fauville G, Strang C, Cannady MA, Chen Y-F (2018) Development of the International Ocean Literacy Survey: measuring knowledge across the world. Environ Educ Res 25:1-26

Fauville G, Strang C, Cannady MA, Chen Y-F (2019) Development of the international ocean literacy survey: measuring knowledge across the world. Environ Educ Res 25(2):238-263

Fernández Otero RM, Bayliss-Brown GA, Papthanassiou M (2019) Ocean literacy and knowledge transfer synergies in support of a sustainable blue economy. Front Mar Sci 6:646

Fielding S, Copley JT, Mills RA (2019) Exploring our oceans: using the global classroom to develop ocean literacy. Front Mar Sci 6:340
Fletcher S, Potts JS, Heeps C, Pike K (2009) Public awareness of marine environmental issues in the UK. Mar Policy 33:370-375

Ford JD, Cameron L, Rubis J, Maillet M, Nakashima D, Wilcox AC, Pearce T (2016) Including Indigenous knowledge and experience in IPCC assessment reports. Nat Clim Chang 6:349-353

Ford JD, Stephenson E, Willox AC, Edge V, Farahbakhsh K, Furgal C, Harper S, Chatwood S, Mauro I, Pearce T, Austin S, Bunce A, Bussalleu A, Diaz J, Finner K, Gordon A, Huet C, Kitching K, Lardeau M-P, McDowell G, McDonald E, Nakoneczny L, Sherman M (2015) Community-based adaptation research in the Canadian Arctic. WIREs Clim Chang 7(2):175-191

Forrester TD, Baker M, Costello R, Kays R, Parsons AW, McShea WJ (2017) Creating advocates for mammal conservation through citizen science. Biol Cons 208:98-105

Friedlander A (2018) Marine conservation in Oceania: past, present, and future. Mar Pollut Bull 135:139-149

Fulton EA, Smith AD, Smith DC, van Putten EI (2011) Human behaviour: the key source of uncertainty in fisheries management. Fish Fish 12(1):2-17

Gal T (2017) An ecological model of child and youth participation. Child and Youth Serv Rev 79:57-64

Garrett JK, White MP, Huang Y, Ng S, Hui Z, Leung C, Tse LA, Fung F, Elliott LR, Depledge MH, Wong MCS (2019) Urban blue space and health and wellbeing in Hong Kong: results from a survey of older adults. Health Place 55:100-110

Gascon M, Zijlema W, Vert C, White MP, Nieuwenhuijsen MJ (2017) Outdoor blue spaces, human health and well-being: a systematic review of quantitative studies. Int $\mathrm{J}$ Hyg Environ Health 220:1207-1221

Gelcich S, Buckley P, Pinnegar JK, Chilvers J, Lorenzoni I, Terry G, Guerrero AM, Castilla JC, Valedebenito A, Duarte CM (2014) Public awareness, concerns, and priorities about anthropogenic impacts on marine environments. ProcNatlAcadSci 111(42):15042-15047

Gibbs SE, Salgado Kent CP, Slat B, Morales D, Fouda L, Reisser J (2019) Cetacean sightings within the great Pacific Garbage Patch. Mar Pollut Bull 49:2021-2027

Gough A (2017) Educating for the marine environment: challenges for schools and scientists. Mar Pollut Bull 124(2):633-638

Green D (2006) "How might climate change affect island culture in the Torres Strait?" CSIRO Mar and Atmos Res CSIRO 011:14

GSMA (2018). “The mobile economy 2018.” GSM Association.

Guess A, Nagler J, Tucker J (2019) Less than you think: prevalence and predictors of fake news dissemintation on Facebook. Sci Adv 5(1):4586

Gurney GG, Blythe J, Adams H, Adger N, Curnock M, Faulkner L, James T, Marshall N (2017) Refefining community based on place attachment in a connected world. PNAS 114(38):10077-10082

Hartley BL, Thompson RC, Paul S (2015) Marine litter education boosts children's understanding and self-reported actions. Mar Pollut Bull 90:209-217

Hecker, S., M. Luckas, M. Brandt, H. Kikillus, I. Marenbach, B. Schiele, A. Sieber, A. J. H. van Vliet, U. Walz and W. 
Wende (2018) "Stories can change the world: citizen communication in practice" In: Citizen science Innovation in Open Science, Society and Policy. Eds S. Hecker, M. Haklay, A. Bowser, Z. Makuch, J. Vogel, A. Bonn, London, UCL Press

Hobart HJ (2019) When we dance the ocean, does it hear us? J Trans American Stud 10:1

Hoegh-Guldberg O, Bruno JF (2010) The impact of climate change on the world's marine ecosystems. Science 328:1523-1528

Hornsey M, Fielding KS (2016) A cautionary note about messages of hope: focusing on progress in reducing carbon emissions weakens mitigation motivation. Global Environ Chang 39:26-34

Hyder K, Townhill B, Anderson LG, Delany J, Pinnegar JK (2015) Can citizen science contribute to the evidence-base that underpins marine policy? Mar Policy 59:112-120

Illingworth, S. (2017). "Delivering effective science communication: Advice from a science communicator." Seminars in Cell and Development Biology.

IPCC (2019). "Special report on the ocean and cryosphere in a changing climate." IPCC Working Group II / IPCC Secretariat: https://www.ipcc.ch/site/assets/uploads/sites/3/ 2019/2011/SROCC_FinalDraft_FullReport.pdf.

Johnson M, Hannah FC, Acton L, Popovici R, Karanth KK, Weinthal E (2014) Network environmentalism: citizen scientists as agents for environmentla advocacy. Global Environ Chang 29:235-245

Jose S, Patrick PG, Moseley C (2017) Experiential learning theory: the importance of outdoor classrooms in environmental education. International $\mathrm{J}$ SciEduc, Part $\mathrm{B}$ 7(3):269-284

Jouffray J-B, Blaskiak R, Norström AV, Österblom H, Nyström $M$ (2020) The blue acceleration: the trajectory of human expansion into the ocean. One Earth 2(1):43-54

Kelly R, Fleming A, Pecl GT (2018) Social licence for marine conservation science. Front Mar Sci 5:414

Kelly R, Fleming A, Pecl GT, Richter A, Bonn A (2019) Social licence through citizen science: a tool for marine conservation. Ecol and Soc 24(1):16

Kelly, R., A. Fleming, G. T. Pecl, J. von Gönner and A. Bonn (2020). Citizen science and marine conservation: A global review. Philosophical Transactions of the Royal Society B.

Kikiloi K, Friedlander AM, Wilhelm A, Lewis Na, Quiocho K, Āila W, Kaho'ohalahala S (2017) Papahānaumokuākea: integrating culture in the design and management of one of the world's largest marine protected areas. Coast Manag 45(6):436-451

Komugabe-Dixson AF, De Ville NSE, Trundle A, McEvoy D (2019) Environmental change, urbanisation and socioecological resilience in the Pacific: community narratives from Port Vila, Vanuata. EcosystServ 39:100973

Koomen MH, Rodriguez E, Hoffman A, Petersen C, Oberhauser K (2018) Authentic science with citizen science and student-driven science fair projects. SciEduc 102(3):593-644

Kopke K, Black J, Dozier A (2019) Stepping out of the ivory tower for ocean literacy. Front Mar Sci 6:60

Kothari A (2008) Protected areas and people: the future of the past. Park International J Prot Area Manag 17(2):23-34

Lahoz-Monfort JL, Chadès I, Davies A, Fegraus E, Game E, Guillera-Arroita G, Harcourt R, Rhodes J, Roe P, Rogers
A, Ward A, Watson DM, Watson JEM, Wintle BA, Joppa L (2019) A call for international leadership and coordination to realize the potential of conservation technology. Bioscience 69:823-832

Laranjo, L., A. Lau, B. Oldenburg, E. Gabarron, A. O’Neill, S. Cha and S. Coiera (2015). "mHealth technologies for chronic disease prevention and management: An evidence review brokered by the Sax Institute for Healthdirect Australia." www.saxinstitute.org.au.

Lavers JL, Bond AL (2017) Exceptional and rapid accumulation of anthropogenic debris on one of the world's most remote and pristine islands. PNAS 114(23):6052-6055

Lazarow N, Miller ML, Blackwell B (2008) The value of recreational surfing to society. Tour Mar Environ $5: 145-158$

Lee HS, Liu SY, Yeh T-K (2019) Marine education through cooperation: a case study of opportunity in a remote school in taiwan exemplary practices in marine science education-a resource for practitioners and researchers. In: Fauville G, Payne DL, Marrero ME, Lantz-Andersson A, Crouch F (eds) International Publishing. Springer, Cham

Lee JJ, Ceyhan P, Jordan-Cooley W, Sung W (2013) GREENIFY: A Real-World Action Game for Climate Change Education. Simulation \& Gaming 44(2-3):349-365

Leicht A, Heiss J, Byun WJ (2018) Issues and trends in education for sustainable development. UNESCO Publishing, France

Lewandowsky S, Ecker UKH, Cook J (2017) Beyond misinformation: understanding and coping with the "post-truth" era. J Appl Res Memory Cog 6:353-369

Li WC, Tse HF, Fok L (2016) Plastic waste in the marine environment: a review of sources, occurrence and effects. Sci Total Environ 566:333-349

Locock, K. E. S., J. Deane, E. Kosior, H. Prabaharan, M. Skidmore and O. E. Hutt (2017). "The recycled plastics market: Global analysis and trends." CSIRO Australia.

Martin L, White MP, Hunt A, Richardson M, Pahl S, Burt J (2020) Nature contact, nature connectedness and assocations with health, wellbing and pro-environmental behaviours. J Environ Psychol 68:101389

Martin VY, Christidis L, Pecl GT (2016) Public interest in marine citizen science: is there potential for growth? Bioscience 66:683-692

McAfee D, Doubleday ZA, Geiger N, Connell SD (2019) Everyone loves a success story: optimism inspires conservation engagement. Bioscience 69(4):274-281

McCauley V, McHugh P, Davison K, Domegan C (2019) Collective intelligence for advancing ocean literacy. Environ Educ Res 25(2):280-291

McKinley E, Acott T, Stojanovic T (2019) Socio-cultural dimensions of marine spatial planning. In: Zaucha J, Gee K (eds) Maritime Spatial Planning. Palgrave Macmilla, Cham

McKinley E, Fletcher S (2010) Individual responsibility for the oceans? an evaluation of marine citizenship by UK marine practitioners. Ocean Coast Manag 56:379-384

McKinley E, Fletcher S (2012) Improving marine environmental health through marine citizenship: a call for debate. Mar Policy 36:839-843

McPherson KL, Wright T, Tyedmers PH (2018) Examining the nova scotia science curriculum for international ocean 
literacy principle inclusion. International J Learn, Teach and Educ Rese 17:11

Meadow AM, Ferguson DB, Guido Z, Horangic A, Owen G, Wall T (2015) Moving toward the deliberative coproduction of climate science knowledge. Weather, Clim and Soc $7: 2$

Medema W, Meyer I, Adamoski J, Wals AEJ, Chew C (2019) The potential of serious games to solve water problems: Editorial to the special issue on game-based approaches to sustainable water governance. Water 11(12):2562

Milhailidis P, Viotty S (2017) Spreadable spectacle in digital culture: civic expression, fake news, and the role of media literacies in "post-fact" society. Am BehavSci 61:441-454

Mogias A, Boubonari T, Realdon G, Previati M, Mokos M, Koulouri P, Cheimonopoulou MT (2019) Evaluating ocean literacy of elementary school students: preliminary results of a cross-cultural study in the Mediterranean Region. Front Mar Sci 6:396

Moltmann T, Zhang HM, Turton JD, Nolan G, Gouldmann CC, Griesbauer L, Willis Z, Muñiz Piniella Á, Charpentier E, Poli P, Burger EF (2019) A Global Ocean Observing System (GOOS) delivered through enhanced collaboration across regions, communities, and new technologies. Front Mar Sci 6:291

Montagnier, P. and A. Wirthmann (2011). "Digital divide: From computer access to online activities-a micro data analysis."

Moreton SG, Arena A, Hornsey M, Crimston C, Tiliopolos N (2019) Elevating nature: morla elevation increases feelings of connectedness to nature. J Environ Psychol 65:101332

Mustonen T (2019) Diving deeper with Indigenous knowledge: oceans and original peoples. J Ocean Technol 14:126-127

NASEM (2018) Learning through citizen science: enhancing opportunities by design. The National Academies Press, Washington DC

Nash KL, et al (2021) Developing achievable alternate futures for key challenges during the UN Decade of Ocean Science for Sustainable Development. Rev Fish Biol Fish

Nichols WJ (2014) Blue mind: the surprising science that shows how being near, in, on or under water can make you happier, healthier, more connected, and better at what you do. Little, Brown and Company, New York, NY

NOAA (2019). "Navigating change." Papahānaumokuakea Marine National Monument.

Norström AV, Cvitanovic C, Österblom H (2020) Principles for knowledge co-production in sustainability research. Nat Sustain 3:182-190

Nursey-Bray M, Palmer R, Pecl GT (2018) Spot, log, map: assessing a marine virtual citizen science program against reed's best practice for stakeholder participation in environmental management. Ocean Coast Manag 15:1-9

Owens KA (2018) Using experiential marine debris education to make an impact: collecting debris, informing policy makers, and influencing students. Mar Pollut Bull 127:804-810

Pahl S, Wyles KJ, Thompson RC (2017) Channelling passion for the ocean towards plastic pollution. Nat Human Behav 1(697):699

Parsons ECM (2016) “Advocacy" and "Activism" are not dirty words - how activists can better help conservation scientists. Front Mar Sci 3:229
Pecl GT, Araújo MB, Bell JD, Blanchard J, Bonebrake TC, Chen I-C, Clark TD, Colwell RK, Danielsen F, Evangård B, Falconi L, Ferrier S, Frusher S, Garcia RA, Griffis RB, Hobday AJ, Janion-Scheepers C, Jarzyna MA, Jennings S, Lenoir J, Linnetved HI, Martin VY, McCormack PC, McDonald J, Mitchell NJ, Mustonen T, Pandolfi JM, Pettorelli N, Popova EE, Robinson SA, Scheffers BR, Shaw JD, Sorte CJB, Strugnell JM, Sunday JM, Tuanmu M-N, Vergés A, Villanueva C, Wernberg T, Wapstra E, Williams SE (2017) Biodiversity redistribution under climate change: impacts on ecosystems and human well-being. Science 355(1389): 1398

Pecl GT, Stuart-Smith J, Walsh P, Bray D, Brians M, Burgess M, Frusher S, Gledhill D, George O, Jackson G, Keane J, Martin VY, Nursey-Bray M, Pender A, Robinson L, Rowling K, Sheaves M, Moltschaniwskyj NA (2019) Redmap Australia: challenges and successes with a largescale citizen science-based approach to ecological monitoring and community engagement on climate change. Front Mar Sci 6:349

Pendleton, L., K. Evans and M. Visbeck (2020). We need a global movement to transform ocean science for a better world. Proceedings of the National Academy of Sciences

Pergams, O. R. W. and P. A. Zaradic (2008). Evidence for a fundamental and pervasive shift away from nature-based recreation. Proceedings of the National Academy of the United States of America 105:2295-2300

PewOceansCommission (2003) "America's living oceans: charting a course for sea change A report to the nation". Pew Oceans Commission Arlington, VA, USA

Pittman SJ, Rodwell LD, Shellock RJ, Williams M, Attrill MJ, Bedford J, Curry K, Fletcher S, Gall SC, Lowther J, McQuatters-Gollop A, Moseley KL, Rees SE (2019) Marine parks for coastal cities: a concept for enhanced community well-being, prosperity, and sustainable city living. Mar Policy 103:160-171

Poloczanska ES, Burrows M, Brown CJ, GarcíaMolinos J, Halpern BS, Hoegh-Guldberg O, Kappel CV, Moore PJ, Richardson AJ, Schoeman D, Sydeman WJ (2016) Responses of marine organisms to climate change across oceans. Front Mar Sci 3:62

Poushter J (2016) Smartphone ownership and internet usage continues to climb in emerging economies. Pew Research Center Global Attitudes Project. 202.419.4372

Roos, P. (2013). "Indigenous knowledge and climate change: the Wathaurong and Gadubanud narrative of the Great Ocean Road region" IFLA 2013: Shared wisdom in an age of change: Proceedings for the International Federation of Landscape Architects 50th World Congress, Auckland NZ

Rousseau, Y., R. A. Watson, J. Blanchard and E. A. Fulton (2019). "Evolution of global maine fishing fleets and the response of fished resources." Proceedings of the National Academy of Sciences

Roy HE, Pocock MJO, Preston CD, Roy DB, Savage J, Tweedle JC, Robinson LD (2012) "Understanding citizen science \& environmental monitoring”. NERC Centre for Ecology \& Hydrology and Natural History Museum, Final report on behalf of UK-EOF

Roy M, Shemdoe R, Hulme D, Mwageni N, Gough A (2018) Climate change and declining levels of green structures: 
life in informal settlements of DAR es Salaam, Tanzania. LandscUrb Plan 180:282-293

Ryfield, F., D. Cabana, J. Brannigan and T. Crowe (2019). "Conceptualising 'sense of place' in cultural ecosystem services: A framework for interdisciplinary research." Ecosystem Services 36.

Sampang AG (2005) Ethnoicthyology and conservation practices of the Calamian Tagbanwa in CoronIslan, Palawan, Philippines. University of Philippines Los Banos, Masters

Santoro, F., S. Santin, G. Scowcroft, G. Fauville and P. Tuddenham (2017). "Ocean literacy for all: A toolkit." IOC Manuals and Guides 80 (IOC/UNESCO \& UNESCO Venice Office, Paris).

Scheufele DA, Krause NM (2019) Science audiences, misinformation and fake news. PNAS 116:7662-7669

Schmidt KM, Kelter P (2017) Science fairs: a qualitative study of their impact on student science inquiry learning and attitudes towards STEM. SciEduc 25(2):126-132

Schoedinger S, Cava F, Strang C, Tuddenham P (2005) Ocean literacy through science standards. Oceans 1(3):736-740

Schoedinger, S., L. Uyen Tran and L. Whitley (2010). "From the principles to the scope and sequence: A brief history of the ocean literacy campaign." NMEA Special Report \#3.

Schubel, J. R. and K. A. Schubel (2008). "From ocean issues to solutions: The role of public ocean literacy." OCEANS.

Schuldt JP, McComas KA, Byrne SE (2016) Communicating about ocean health: theoretical and practical considerations. Philos Trans Royal Soc B: BiolSci 371:201450214

Serra-Gonçalves C, Lavers JL, Bond AL (2019) Global review of beach debris monitoring and future recommendations. Environ SciTechnol 53(21):12158-12167

Shirk, J. and R. Bonney (2015). "Informing a framework for citizen science within the US Fish and Wildlife Service." An independent science review conducted for the Consensus Building Institute on behalf of the US Institute.

Silverstone, R. (2017) "Media, technology and everyday life in Europe: From information to communication." Routledge; 1 edition (June 20, 2005)

Sloan J, Chand K (2016) An analysis of property rights in the Fijian goligoli. Mar Policy 72:76-81

Soares, M. (1998). "The ocean: Our future." Cambridge University Press.

Song Z, Daryanto A, Soopramanien D (2019) Place attachment, trust and mobility: three-way interaction effect on urban residents' environmental citizenschip behaviour. J Bus Res 105:165-177

Stafford R, Jones PJS (2019) Ocean plastic pollution: a convenient but distracting truth? Mar Policy 103:187-191

Stewart BD, Howarth LM, Wood H, Whiteside K, Carney W, Crimmins E, O’Leary BC, Hawkins JP, Roberts C (2020) Marine conservation begins at home: how a local community and protection of a small bay sent waves of change around the UK and beyond. Front in Mar Sci 7:76

Stoll-Kleemann S (2019) Feasible options for behaviour change toward more effective ocean literacy: a systematic review. Front in Mar Sci 6:273

TebrakunnaCountry, Lee E (2019). "'Reset the realtionship': Decolonising government to increase Indigenous benefit." Cultural Geographies 1-20
Thornton TF, MaciejewskiScheer A (2012) Collaborative engagement of local and traditional knowledge and science in marine environments: a review. Ecol Soc 17(3):8

Truong MA, Clayton S (2020) Technologically transformed experiences of nature: a challenge for environmental conservation? Biol Cons 244:108532

UN (2018a). "Revised Roadmap for the UN Decade of Ocean Science for Sustainable Development." IOC. Executive Council, 51st, Paris, 2018 Intergovernmental Oceanographic Commission.

UN (2018) "The world's cities in 2018 - data booklet (ST/ESA/ SER.A/417)". United Nations, Department of Economic and Social Affairs, Population Division

UN (2019a). "Digital economy report 2019. Value creation and capture: Implications for developing countries."

UN (2019b). "https://www.oceandecade.org/."

UNESCO (2006). "Literacy for life. EFA Global Monitoring report."

UNESCO (2009). "Investing in Cultural Diversity (Vol 2). Riviére, F. ed.".

van der Mheen M, Pattiaratchi C, van Sebille E (2019) Role of Indian Ocean dynamics on accumulation of buoyant debris. J Geophy Res: Oceans 124:2571-2590

van der Molen F, Puente-Rodriguez D, Swart AA, van der Windt HJ (2015) The co-production of knowledge and policy in coastal governance: integrating mussel fisheries and nature restoration. Ocean Coast Manag 109:49-60

van Putten EI, Plagányi ÉE, Booth K, Cvitanovic C, Kelly R, Punt AE, Richards SA (2018) A framework for incorporating sense of place into the management of marine systems. Ecol and Soc 23(4):4

Villarrubia-Gómez P, Cornell SE, Fabres J (2018) Marine plastic pollution as a planetary boundary threat - the drifting piece in the sustainability puzzle. Mar Policy 96:213-220

Vince J, Hardesty BD (2016) Plastic pollution challenges in marine and coastal environments: from local to global governance. Restor Ecol 25(1):123-128

Vince J, Hardesty BD (2019) Governance solutions to the tragedy of the commons that marine plastics have become. Front Mar Sci 5:214

Vromen A, Colin P (2010) Everday youth participation? contrasting views from Australian policymakers and young people. Young 18(1):97-112

Walsh JC, Dicks LV, Raymond CM, Sutherland WJ (2019) A typology of barriers and enablers of scientific evidence use in conservation practice. J Environ Manag 250:109481

Wiener CS, Manset G, Lemus JD (2016) Ocean use in Hawaii as a predictor of marine conservation interests, beliefs, and a willingness to participate: an exploratory study. J Environ Stud Sci 6:712-723

Wu JS, Lee JJ (2015) Climate change games as tools for education and engagement. Nat Clim Chang 5:413-418

Wulff A, Johannesson K (2019) bring the ocean to the classroom-introducing experimental studies to teachers with fair or no science knowledge exemplary practices in marine science education: a resource for practitioners and researchers. In: Fauville G, Payne DL, Marrero ME, LantzAndersson A, Crouch F (eds) International Publishing. Springer, Cham 
Young JC, Jordan A, Searle KR, Butler A, Chapman DS, Simmons P, Watt AD (2013) Does stakeholder involvement really benefit biodiversity conservation? Biol Cons 158:359-370

Zardo P, Barnett AG, Suzor N, Cahill T (2018) Does engagement predict research use? an analysis of the conversation annual survey 2016. PLoS ONE 13(2):e0192290

Zurba M, Berkes F (2014) Caring for country through participation art: creating a boundary object for communcating
Indigenous knowledge and values. Local Environ 19(8):821-836

Publisher's Note Springer Nature remains neutral with regard to jurisdictional claims in published maps and institutional affiliations. 